\title{
Evaluation of semen collected from commercial rams by electro-ejaculation
}

Authors: Lovatt, F.M., Genever, L., Glover M.J., Henry, J.

Abstract

Annual ram pre-breeding soundness examinations (PBSE) are accepted as an integral component of veterinary flock health planning to identify rams not capable of achieving high conception rates. This preliminary study collected information from 280 rams presented to five veterinarians for routine PBSE on commercial farms in England in 2013. The study compared the outcome of a physical examination, which included palpation of external genitalia, with the gross and progressive motility of the semen produced by electro-ejaculation.

Short Communication (1137 words)

Annual ram pre-breeding soundness examinations (PBSE) are accepted as an integral component of veterinary flock health planning to identify rams not capable of achieving high conception rates. This preliminary study collected information as to current practice on commercial farms with the aim of contributing to the development of 'best practice' guidelines (anon 2014).

Records were collected from 280 rams presented for routine PBSE in autumn 2013 to five first-opinion veterinarians, one in the south west of England and four from one practice in north east England. The study population consisted of all rams on 20 farms and only newly-purchased rams on four farms. In accordance with usual practice, each ram was physically examined, external genitalia were palpated and semen was collected by electro-ejaculation on up to two separate occasions. Findings were recorded on standard data collection forms. Maximum scrotal circumference was measured in centimetres using a tensioned tape measure (Reliabull; Lane).

The vets in the north-east worked alone, using a Lane electro-ejaculator and bright field microscopy with a green filter and low condenser and the vet in the south west used a technician to handle the semen, a Medata electroejaculator and a phase-contrast microscope. All glass equipment was warmed to $30-37^{\circ} \mathrm{C}$, the microscope stage to $35-37^{\circ} \mathrm{C}$, and the sample volume was measured to the nearest $0.2 \mathrm{ml}$. The semen sample was assessed for gross density, on a scale of one (water) to five (thick cream), gross motility (on a scale of one to five at 40x and 100x magnification) and progressive motility of a sample diluted in phosphate buffered saline under 100x and 200x magnification. Data was collated using Excel (Microsoft 2010). The vet recorded their recommendations to the farmer as satisfactory ('OK'), unsatisfactory ('not OK') or whether a retest was advised as based on their current practice. Statistical analysis was performed using a Fisher's exact test to compare recommendations between the vets at different locations and $p$-values $<0.05$ were considered significant. No data was collected as to the proportion of ewes which conceived when the rams were used.

Nineteen breeds were represented of which the major types were Texel (70 rams), Suffolk (65), Blue-faced Leicester (38), Lleyn (25), Beltex (18) and Primera (13). All the Primera rams were in the south-west sample. $17.6 \%$ of rams were below condition score 3 and 2.2\% were above condition score 4 out of a total score of 5 .

The following areas were examined, with the percentage of rams scored as abnormal given in parentheses: feet $(17.6 \%)$, teeth (12.7\%), rest of body (5.5\%), brisket (5.4\%), penis (1.9\%), scrotum (3.9\%) and prepuce (1.1\%). Left 
and right testicles were scored as 'soft' for $7.4 \%$ and $7.7 \%$, and 'small' for $4.9 \%$ and $5.6 \%$ of rams respectively. The epididymes were considered abnormal in the left head in $1.8 \%$ of rams and in the left tail, right head or right tail in $2.1 \%$ of rams each.

Semen quality was considered 'questionable' if gross motility scored less than three out of five or progressive motility was less than $50 \%$. This was recorded for $41 \%$ of rams with abnormal testicle size; for $57 \%$ rams with abnormal testicle tone; for $75 \%$ of rams with abnormal head of epididymis; and for $86 \%$ of rams with an abnormal tail of epididymis on either the left or right side.

Scrotal circumference (SC) ranged from $26 \mathrm{~cm}$ to $44 \mathrm{~cm}$ with a mean and median circumference of $37 \mathrm{~cm}$ and a mode of $38 \mathrm{~cm}$. When ram lambs, shearlings and hill breeds were removed from the sample, there were 37 out of 168 rams (22\%) with a SC of less than $36 \mathrm{~cm}$; three of these rams produced questionable semen sample and two were recommended for a re-test. Scrotal circumference was $36-38 \mathrm{~cm}$ for $68(41 \%)$ rams and above $38 \mathrm{~cm}$ for 62 (37\%) rams.

Of the 280 rams, veterinarians considered that 235 (83.9\%) rams were suitable ("OK") for breeding that season. Thirty six (12.9\%) rams were considered not suitable ("not OK"), and the suitability of nine (3.2\%) rams was considered questionable with the recommendation of retesting at a later date. There was a significant difference (Fishers Exact; $p=0.011$ ) in the number of rams recommended to be retested by the south west vet $(12.9 \%)$ compared to the north east vets (2.0\%). There was no significant difference between vets in the proportions of rams that were classified as either ' $O K^{\prime}$ ' (Fishers Exact; $p=0.3$ ) or 'not $\mathrm{OK}^{\prime}(\mathrm{p}=0.8)$. In the north east, seven rams, that were considered 'not OK', had a scrotal circumference above $36 \mathrm{~cm}$ with no recorded physical abnormalities or abnormalities of the external genitalia.

In this study, $84 \%$ of rams were considered fit for breeding which was more than the $71.1 \%$ suggested by a large study in Western USA (Van Metre et al., 2012) though in that study $20 \%$ of failures were attributed to 'inflammatory causes' which included cases of Brucella ovis, a disease not present in the UK (Sargison 2008).

It is important to determine the validity of a decision made from genital palpation for veterinarians or farmers without access to electro-ejaculation and in this study the semen sample was questionable $41-86 \%$ of the time a genital abnormality was palpated. This figure is considerably higher than the $13-38 \%$ found in previous studies (Edgar, 1959, Barr, 1984) and would support the suggestion that a ram with a palpable genital abnormality should not be relied upon for breeding (Boundy, 1992, Sargison, 2008).

Although there was space on the data collection form for recording sperm morphology, this was not undertaken for the majority of rams in this study which possibly reflects veterinarians usual practice for commercial rams. Best practice guidance suggests that, for certification purposes, PBSE of rams should include examination of sperm morphology (Boundy, 1992, 1993, Penny, 2010, anon, 2014).

The divergence between vets in the number of rams that were recommended to be retested may reflect farm, breed or regional factors or may reflect different operator approaches to interpretation of PBSE. There is evidence to show that electro-ejaculation may fail to produce satisfactory semen samples from rams of normal fertility on up to $18 \%$ of 
occasions and a ram should not be considered unsuitable for breeding unless it produces an unsatisfactory semen sample three times over a period of six weeks (Edgar, 1959, 1963). Arguably the rams in this study that were considered unsuitable for breeding based solely upon the production of a single unsatisfactory semen sample should have been retested.

This study supports the latest Sheep Veterinary Society advice (anon 2014) which recommends that routine electroejaculation and evaluation of semen provides appropriate additional information when rams are to be used in high pressure situations, such as single sire mating or with large numbers of ewes but that it may not be appropriate in low pressure situations. A ram should not be considered unsuitable for breeding based on the collection of a single questionable semen sample on a single day and it is important that the reason why is clearly explained to the farmer.

This study was funded by the Agriculture and Horticulture Development Board through its Beef and Lamb division.

\section{References}

ANON. 2014. Sheep Veterinary Society - Guidelines on the examination of rams for breeding [Online]. Sheep Veterinary Society. [Accessed 12th November 2014].

BARR, W. M. 1984. ASSESSMENT OF RAM FERTILITY IN HILL FLOCKS IN ARGYLL. Veterinary Record, 114, 587-590.

BOUNDY, T. 1992. Routine ram examination. In Pract., 14, 219-228.

BOUNDY, T. 1993. Collection and interpretation of ram semen under general practice conditions. In Pract., 15, 219223.

EDGAR, D. G. 1959. Examination of rams for fertility. New Zealand Veterinary Journal, 7, 61-63.

EDGAR, D. G. 1963. The place of ram testing in the sheep industry. New Zealand Veterinary Journal, 11, 113-115.

PENNY, C. 2010. The BCVA's bull pre-breeding examination certificate. The Veterinary Record, 551-554.

SARGISON, N. 2008. Sheep Flock Health - A Planned Approach, Blackwell Publishing.

VAN METRE, D. C., RAO, S., KIMBERLING, C. V. \& MORLEY, P. S. 2012. Factors associated with failure in breeding soundness examination of Western USA rams. Preventive Veterinary Medicine, 105, 118-126. 